\title{
PARTISIPASI MASYARAKAT PADA PEMBANGUNAN INFRASTRUKTUR JALAN PERTANIAN MELALUI (PNPM-PPIP) DI DESA KINI KECAMATAN HILIPUK KABUPATEN YAHUKIMO
}

\author{
Yakobus Bahabol \\ Caroline B. D. Pakasi \\ Jean F. J. Timban
}

\begin{abstract}
This study aims to what extent the community involvement in the development of agricultural road infrastructure through the PNPM-PPIP program. This study lasted for 3 months from September until November 2017. The research location is in Kini Village, Hilipuk Sub-District, Yahukimo Regency. The type of data were collected in this research is primary data and secondary data. Selection of the sample used purposive sampling method. The number of respondents is 20 people who are Community Leaders in the implementation of Local Community Organization (CSO) activities. The analysis technique used in this research is qualitative descriptive. The results showed that community participation in the development of agricultural road infrastructure in Kini Village is in the medium category. Because of the three stages of infrastructure development, only the maintenance phase is the stage that involves the most participation of the community while the planning stage and the implementation stage there is no participation from the community. Community involvement in the maintenance phase because at this stage the community has felt the result of the development of agricultural road access infrastructure. *eprm*.
\end{abstract}

Keywords: community participation, agricultural road infrastructure development, PNPM-PPIP, Kini Village, Hilipuk Sub-District, Yahukimo Regency.

\begin{abstract}
ABSTRAK
Penelitian ini bertujuan untuk melihat sejauh mana partisipasi masyarakat terhadap pembangunan infrastruktur jalan pertanian melalui program PNPM-PPIP. Penelitian ini berlangsung selama 3 bulan sejak bulan September sampai bulan November 2017. Tempat penelitian di Desa Kini, Kecamatan Hilipuk, Kabupaten Yahukimo. Data yang dikumpulkan dalam penelitian ini adalah data primer dan data sekunder. Pemilihan sampel menggunakan metode secara sengaja (purposive sampling). Jumlah responden sebanyak 20 orang yang merupakan Tokoh Masyarakat dalam pelaksanaan kegiatan Organisasi Masyarakat Setempat (OMS). Teknik analisis yang digunakan dalam penelitian ini adalah teknik analisis deskriptif kualitatif. Hasil penelitian menunjukkan bahwa partisipasi masyarakat dalam pembangunan infrastruktur jalan pertanian di Desa Kini, berada pada kategori yang sedang. Karena dari ketiga tahapan pembangunan infrastruktur hanya tahap pemeliharaan merupakan tahapan yang paling banyak melibatkan partisipasi masyarakat sedangkan tahap perencanaan dan tahap pelaksanaan tidak ada partisipasi dari masyarakat. Keterlibatan masyarakat dalam tahap pemeliharaan karena pada tahapan ini masyarakat telah merasakan hasil dari pembangunan infrastruktur akses jalan pertanian.
\end{abstract}

Kata kunci: partisipasi masyarakat, pembangunan infrastruktur jalan pertanian, PNPM-PPIP, Desa Kini, Kecamatan Hilipuk, Kabupaten Yahukimo. 


\section{PENDAHULUAN}

\section{Latar Belakang}

Undang-Undang Nomor 32 tahun 2004, paradigma pembangunan nasional telah mengalami suatu perubahan yang signifikan, dari pembangunan yang bertumpu pada Negara menjadi paradigma pembangunan yang berkembang pada masyarakat perdesaan, pembangunan Infrastruktur Perdesaan (PPIP) yang bertujuan untuk menciptakan dan meningkatkan kesejahteraan masyarakat, baik secara individu maupun kelompok sehingga masyarakat mampu memecahkan berbagai permasalahan terkait kemiskinan dan ketertinggalan yang ada di desa, PPIP merupakan program berbasis pemberdayaan masyarakat di bawah payung PNPM Mandiri, yang komponen kegiatannya meliputi dan mobilisasi masyarakat sehingga masyarakat mampu melakukan identifikasi permasalahan ketersediaan dan akses menuju infrastruktur jalan pertanian.

Partisipasi masyarakat dalam pembangunan infrastruktur merupakan keterlibatan anggota masyarakat dalam pembangunan, meliputi kegiatan dalam program atau proyek pembangunan yang dikerjakan oleh masyarakat lokal, partisipasi atau peran serta masyarakat dalam pembangunan infrastruktur jalan pertanian dapat diartikan sebagai aktualisasi dari kesediaan dan kemampuan anggota masyarakat untuk berkorban dan berkontribusi dalam implementasi program atau proyek kepada masyarakat (Adisasmita, 2006).

Tujuan dari pembangunan infrastruktur jalan pertanian untuk mengakseskan bagi petani agar melancarkan hasil perekonomian mereka, oleh karena itu di harapkan peran serta masyarakat perlunya bentuk partisipasi yang di memberi pengaruh terhadap kelancaran pada program PNPM-PPIP, dalam hal ini kontribusi dalam bentuk apapun akan di terima, sehingga masyarakat akan merasa lebih bertanggung jawab untuk menjaga dan memanfaatkan dengan baik. Itu sebab partisipasi dapat berjalan lancar bila masyarakat memberikan kontribusi dalam proses kegiatan. Melalui berbagai macam bentuk pasrtisipasi inilah masyarakat bisa ikut terlibat dan dapat bertanggung jawab atas program yang di berikan oleh pemerintah daerah.

Program Pembangunan Infrastruktur Perdesaan (PPIP) Tahun 2016, merupakan bagian dari PNPM Mandiri dialokasikan untuk setiap kepala kampung 517 Desa/kepala kampung dari 51 Distrik di Kabupaten Yahukimo Provinsi Papua. Program ini juga menekankan bahwa partisipasi masyarakat dalam proses kegiatan Program Pembangunan Infrastruktur jalan pertanian Tahun 2016, dititik beratkan penanganan pada desa yang tertinggal yang memiliki pelayanan infrastruktur yang paling rendah.

Program PNPM-PPIP diadakan hampir diseluruh perdesaan wilayah Papua dan salah satunya dilaksanakan di Desa Kini yang menjadi jenis kegiatan adalah pembangunan jalan pertanian, dan berupa jalan tanah. Dengan angaran yang digunakan dalam pembangunan ini adalah Rp.300.000.000 (tiga ratus juta), dimana Rp.300.000.000 tersebut dana bantuan dari pemerintah melalui PNPMPPIP oleh karena itu pemerintah Desa memperlibatkan semua masyarakat untuk membangun jalan pertanian untuk mengakseskan hasil perekonomian, sehingga jalan tersebut sangat membantu masyarakat untuk melancarkan hasil perekonomian mereka.

\section{Perumusan Masalah}

Berdasarkan latar belakang diatas, maka yang menjadi rumusan masalah dalam penelitian ini adalah bagaimana tingkat partisipasi masyarakat terhadap program pembangunan infrastruktur jalan pertanian di Desa Kini.

\section{Tujuan Penelitian}

Tujuan dari penelitian ini adalah untuk melihat seberapa besar partisipasi masyarakat terhadap pembangunan infrastruktur jalan pertanian melalui program PNPM-PPIP di Desa Kini Kecamatan Hilipuk Kabupaten Yahukimo. 


\section{Manfaat Penelitian}

Penelitian ini diharapkan dapat bermanfaat bagi:

1. Masyarakat

Menambahkan pengetahuan kepada masyarakat agar masyarakat dapat memahami tentang program PNPM-PPIP.

2. Penulis

Selain untuk penyelesaian studi akhir, juga dapat menambahkan pemahaman dan pengetahuan kepada penulis tentang bagaimana partisipasi masyarakat terhadap pembangunan infrastruktur jalan pertanian.

\section{METODE PENELITIAN}

\section{Tempat dan Waktu Penelitian}

Penelitian ini berlangsung selama 3 bulan sejak bulan September sampai bulan November 2017. Tempat penelitian di Desa Kini Kecamatan Hilipuk Kabupaten Yahukimo.

\section{Metode Pengumpulan Data}

Data yang digunakan dalam penelitian ini adalah data primer dan data sekunder. Data primer merupakan data yang diperoleh dari lapangan tempat penelitian melalui daftar pertanyaan atau kuesioner. Data sekunder yaitu data yang diperoleh dari pemerintah Desa Kini, serta karya tulis ilmiah yang berhubungan dengan penelitian.

\section{Metode Pengambilan Sampel}

Pengambilan sampel mengunakan metode purposive sampling, jumlah responden sebanyak 20 orang yang merupakan Tokoh Masyarakat, dalam pelaksanaan kegiatan, (OMS) Organisasi Masyarakat Setempat.

\section{Konsep Pengukuran Variabel}

Variabel yang diukur dalam penelitian ini adalah:

1. Karakteristik dari masyarakat
a. Umur Responden
b. Pekerjaan Responden
c. Tingkat Pendidikan Responden

2. Partisipasi responden dalam Program Pembangunan Infrastruktur Perdesaan yang dilaksanakan dari
A. Tahap Perencanaan

1. Yang Aktif (3) Responden memberikan partisipasi dalam bentuk

a. Kehadiran dimana responden hadir setiap pertemuan sebanyak 3 kali dari 3 kali pertemuan.

b. Keaktifan dalam pertemuan responden tersebut selalu memberikan saran atau usulan di setiap rapat.

2. Yang kurang Aktif (2) Responden memberikan partisipasi dalam bentuk

a. Kehadiran dimana responden hadir setiap pertemuan sebanyak 2-1 kali dari 3 kali pertemuan.

b. Keaktifan dalam pertemuan responden tersebut selalu memberikan saran atau usulan di setiap rapat.

3. Yang tidak Aktif (1) Responden memberikan partisipasi dalam bentuk apapun. Apapun karena responden tersebut kurang hadir dalam setiap perteuan.

B. Tahap Pelaksanaan

1. Yang Aktif (3) Responden memberikan partisipasi dalam bentuk.

a. Partisipasi dalam bentuk tenaga dimana responden mengambil bagian dalam setiap kegiatan.

b. Partisipasi berupa benda dimana kegiatan responden membawa peralatan setiap pelaksanaan kegiatan.

2. Yang kurang Aktif (2) Responden memberikan dalam bentuk.

a. Partisipasi dalam bentuk tenaga dimana responden mengambil bagian dalam setiap kegiatan.

b. Partisipasi berupa benda dimana kegiatan responden membawa peralatan setiap pelaksanaan kegiatan.

3. Yang tidak Aktif (1) Responden tidak memberikan partisipasi dalam bentuk apapun.

C. Tahap Pemeliharaan

1. Yang Aktif (3) Responden memberikan partisipasi dalam bentuk. 
a. Partisipasi dalam bentuk tenaga dimana responden mengambil bagian dalam setiap kerja bakti.

b. Partisipasi air atau kue dimana responden memberikan air atau kue untuk snack pagi saat kegiatan.

2. Yang kurang Aktif (2) Responden memberikan dalam bentuk.

a. Partisipasi tenaga dimana kegiatan responden tidak selalu mengikuti kerja bakti.

b. Partisipasi air atau kue dimana responden mengambil bagian dalam setiap kerja bakti.

3. Yang tidak Aktif (1) Resopnden tidak memberikan partisipasi dalam bentuk apapun.

Jumlah skor yang berada pada aktif yaitu 3 yang kurang aktif 2 dan yang tidak aktif 1 . Tingkat partisipasi masyarakat ditentukan dengan total skor partisipasi dari setiap masingmasing tingkatan yaitu tinggi, sedang dan rendah.

Tingkat partisipasi diukur dengan penjumlah skor dari variabel, berdasarkan jumlah skor dari semua variabel, dapat diketahui tingkat partisipasi masyarakat masuk dalam tiga karakteristik partisipasi arnstein besarnya interval skor untuk menentukan kategori tingkat partisipasi individu dikalikan dengan jumlah sampel, penjelasan secara rinci sebagai berikut: Terdapat 3 tahap untuk melihat tingkat partisipasi individu dengan skor masingmasing berkisar 1 sampai 3. Sehingga minimum skor yang diperoleh untuk setiap individu (3x3) 9, dengan jumlah sampel 20, dapat diketahui skor minimum untuk tingkat partisipasi masyarakat $(20 \times 3)$ adalah 60 dan skor maksimum ( $20 \times 9)$ adalah 180 . Dengan diketahui skor minimum dan maksimum maka diketahui pula jarak inreval, yaitu (18060).

\section{Metode Analisis Data}

Teknik analisis yang digunakan dalam penelitian ini adalah teknik analisis deskriptif kualitatif.

\section{HASIL DAN PEMBAHASAN}

\section{Deskripsi Daerah Penelitian Letak Geografis, dan Luas Wilayah, Batas}

\section{Administrasi Kalimatologi}

Desa Kini adalah salah satu Desa yang terletak di Kecamatan Hilipuk Kabupaten Yahukimo Provinsi Papua dengan luas wilayah di Desa Kini adalah 33.27 km, dengan batas wilayah:

1. Sebelah Timur : Desa Dindok

2. Sebelah Barat : Desa Ilia

3. Sebelah Selatan : Desa Yaruhuk

4. Sebelah Utara : Desa Yamin

Secara administratif Desa Kini adalah hanya dusun, sebagaimana pada umumnya di wilayah tropis, curah hujan pada bulan Juni sampai dengan bulan Agustus di wilayah ini sangat tinggi dapat mencapai sekitar 2000-3000 $\mathrm{mm}$ pertahun dan suhu bervariasi antara $18^{\circ} \mathrm{C}$ $30^{\circ} \mathrm{C}$. Curah hujan tertinggi mencapai 675,18 $\mathrm{mm}$ terjadi pada bulan Juni sampai dengan bulan Agustus, sedangkan hujan terendah terjadi pada bulan September dan pertengahan bulan Oktober yaitu 214,20 mm. Dengan kondisi wilayah seperti ini sehingga masyarakat sangat memahami dari bulan Januari sampai dengan bulan Mei kemarau dan bulan Juni sampai dengan bulan Agustus hujan.

\section{Jumlah Penduduk di Desa Kini}

Berdasarkan data Pemetaan jumlah penduduk di Desa Kini adalah sebanyak 967.826 jiwa dengan jumlah kepala keluarga $250(\mathrm{KK})$

Tabel 1. Jumalah Penduduk di Desa Kini

\begin{tabular}{lcc}
\hline Jenis Kelamin & Jumlah & Presentase (\%) \\
\hline Laki-laki & 967 & 53,93 \\
Perempuan & 826 & 46,07 \\
\hline Total & 1.793 & 100 \\
\hline
\end{tabular}

Pada Tabel 1 dapat dilihat bahwa jumlah penduduk laki-laki sangat besar dari pada jumlah penduduk perempuan. Jumlah penduduk laki-laki yang lebih banyak yaitu 967 sedangkan jumlah perempuan 826 orang atau $\%$. Persentase, maka penjelasan disini bahwa jumlah yang tertinggi adalah laki-laki. 


\section{Karakteristik Responden}

\section{Umur Responden}

Berdasarkan dengan umur yang mempengaruhi tingkat partisipasi masyarakat. terdapat perbedaan kedudukan dan derajat atas dasar dengan bervariasi, sehingga memunculkan usia tua dan muda, maka Produktivitas seseorang dapat dipengaruhi oleh umur, yaitu umur yang lebih muda tingkat produktivitas tinggi sedang umur dan tahun tingkat produktivitas lebih rendah hasil penelitian di Desa Kini, umur responden dapat dilihat pada Tabel 2.

Tabel 2. Jumlah Responden Menurut Umur

\begin{tabular}{lrcc}
\hline No. & Umur & Jumlah (Responden) & Persentase $(\%)$ \\
\hline 1. & $30-40$ & 8 & 40 \\
2. & $41-50$ & 6 & 30 \\
3. & $51-60$ & 3 & 15 \\
4. & $>60$ & 3 & 15 \\
\hline & Total & 20 & 100 \\
\hline
\end{tabular}

Tabel 2 melihat bahwa persentase yang terbesar yaitu umur $30-40$ tahun sebanyak 8 orang dengan jumlah persentase $40 \%$ sedangkan umur 40 - 50 tahun sebanyak 6 orang, yang memiliki nilai persentase $30 \%$ sedangkan umur 51 - 60 Tahun 3 orang dengan jumlah persentase $15 \%$ dan umur $>60$ tahun sebanyak 3 orang dengan jumlah persentase $15 \%$. Maka penjelasan dari umur persentase yang terbanyak adalah $40 \%$.

\section{Pekerjaan Responden}

Pekerjaan merupakan partisipasi masyarakat dimana memiliki pekerjaan yang lebih tinggi dan juga jabatan yang berbeda setiap responden tingkat partisipasinya memiliki tingkat yang berbeda yaitu Petani dan PNS.

\begin{tabular}{|c|c|c|c|}
\hline \multicolumn{4}{|c|}{$\begin{array}{l}\text { 3. Jumlah Respc } \\
\text { Pekerjaan }\end{array}$} \\
\hline No. & Pekerjaan & $\begin{array}{c}\text { Jumlah } \\
\text { (Responden) }\end{array}$ & $\begin{array}{l}\text { Persentase } \\
(\%)\end{array}$ \\
\hline 1. & Petani & 18 & 90 \\
\hline 2. & PNS & 2 & 10 \\
\hline & Total & 20 & 100 \\
\hline
\end{tabular}

Dari Tabel 3 menunjukkan bahwa menurut pekerjaan, responden merupakan petani yaitu dimana ada 18 orang atau $90 \%$ dan dimana ada 2 orang atau $10 \%$ yang memiliki pekerjaan yang berbeda yaitu petani dan PNS.

\section{Tingkat Pendidikan}

Salah satu faktor yang mempengaruhi pada tingkat pengetahuan adalah tingkat pendidikan, maka pendidikan semakin berkembang dan semakin tinggi latar belakang pendidikan mereka, mempunyai pengetahuan yang luas mengenai pembangunan, maka pendidikan sangat penting karena begitu memiliki pengetahuan yang luas maka bisa berkomunikasi dengan pemerintah dan bisa menanggapi dengan secepatnya. Dapat dilihat pada Tabel 4.

Tabel 4. Jumlah Responden Menurut Pendidikan

\begin{tabular}{llcc}
\hline No. & $\begin{array}{c}\text { Tingkat } \\
\text { Pendidikan }\end{array}$ & $\begin{array}{c}\text { Jumlah } \\
\text { (Responden) }\end{array}$ & $\begin{array}{c}\text { Persentase } \\
(\%)\end{array}$ \\
\hline 1. & SD & 9 & 45 \\
2. & SMP & 4 & 20 \\
3. & SMA & 5 & 25 \\
4. & PT & 2 & 10 \\
\hline & Total & 20 & 100 \\
\hline
\end{tabular}

Dari Tabel 4 menujukan bahwa tingkat pendidikan responden yaitu pada tingkat SD sebanyak 9 orang, tingkat SMP sebanyak 4 orang, dan tingkat SMA sebanyak 5 orang lalu tingkat PT sebanyak 2 orang.

\section{Partisipasi Responden dalam Program Pembangunan Infrastruktur Jalan Pertanian}

\section{Tahap Perencanaan}

Dalam tahap perencanaan pembangunan infrastruktur jalan pertanian yang terlibat dalam keikutsertaan oleh semua masyarakat melalui tahap-tahap dalam program tersebut yaitu dimulai dari penggalian sampai pemeliharaan, dengan gotong royong bentuk partisipasi, dalam tahap perencanaan adalah kehadiran dalam rapat serta keaktifan dalam memberi saran/usulan dimana jenis partisipasi ini lebih kesubangan pikiran oleh masyarakat. 
Tabel 5. Bentuk Partisipasi Masyarakat dalam Tahap Perencanaan

\begin{tabular}{llcc}
\hline No. & \multicolumn{1}{c}{ Bentuk Partisipasi } & $\begin{array}{c}\text { Jumlah } \\
\text { (Responden) }\end{array}$ & $\begin{array}{c}\text { Persentas } \\
(\%)\end{array}$ \\
\hline 1. & $\begin{array}{l}\text { Kehadiran dan } \\
\text { memberi Saran/Usulan }\end{array}$ & 4 & 20 \\
2. & $\begin{array}{l}\text { Kehadiran } \\
\text { Tidak Memberi }\end{array}$ & 16 & 80 \\
Partisipasi & - & \\
\hline & Total & 20 & 100 \\
\hline
\end{tabular}

Dari Tabel 5 menunjukkan bahwa 4 orang atau 20\% memberikan partisipasi melalui kehadiran serta memberikan saran/usulan dalam setiap pertemuan, sedangkan 16 orang atau $80 \%$ hanya hadir saja.

Tabel 6. Jumlah Responden Menurut Partisipasi Masyarakat Terhadap PPIP Pada Tahap Perencanaan

\begin{tabular}{llcc}
\hline No. & $\begin{array}{c}\text { Partisipasi } \\
\text { Masyarakat }\end{array}$ & $\begin{array}{c}\text { Jumlah } \\
\text { (Responden) }\end{array}$ & $\begin{array}{c}\text { Persentase } \\
(\%)\end{array}$ \\
\hline 1. & Aktif & 2 & 10 \\
2. & Kurang Aktif & 15 & 75 \\
3. & Tidak Aktif & 3 & 15 \\
\hline & Total & 20 & 100 \\
\hline
\end{tabular}

Dari Tabel 6 hasil kuesionr yang diberikan kepada responden berkaitan dengan berpartisipasi pada tahap perencanaan melalui Program Pembangunan Infrastruktur Perdesaan (PPIP), yang aktif jumlah sebanyak 2 orang atau $10 \%$ lalu yang kurang aktif 15 orang atau $75 \%$, sedangkan yang tidak aktif 3 orang atau $15 \%$ responden tidak ikut atau tidak aktif berpartisipasi. Seperti terlihat pada Tabel 6, pada kegiatan perencanaan dalam pertemuan desa merupakan bentuk partisipasi masyarakat melalui kehadiran dalam pertemuan, dan setiap masyarakat memberikan ide mengenai infrastruktur jalan pertanian yang akan dibangun dengann tenaga fisik namun sebanyak yang tidak aktif dalam tahap ini karena masyarakat sebagian besar sibuk dengan pekerjaan masing-masing.

Tabel 7. Jumlah Responden dan Partisipasi Masyarakat Menurut Umur
Terhadap Program Pembangunan Infrastruktur Jalan Pertanian
Pada Tahap Perencanaan
\begin{tabular}{lcccccc}
\hline No. & Umur & Aktif & Kurang Aktif & Tidak Aktif & Jumlah & Persentase (\%) \\
\hline 1. & $30-40$ & 2 & 2 & 3 & 7 & 35 \\
2. & $41-50$ & 1 & 1 & 2 & 4 & 20 \\
3. & $51-60$ & - & 3 & 2 & 5 & 25 \\
4. & $>60$ & 2 & - & 2 & 4 & 20 \\
\hline & Total & 5 & 6 & 9 & 20 & 100 \\
\hline
\end{tabular}

Tabel 7 menunjukkan bahwa partisipasi masyarakat terhadap PPIP pada tahap perencanaan berdasarkan kategori. Pada umur 30-40 tahun yang aktif 2 orang, yang kurang aktif 2 orang, lalu yang tidak aktif 3 orang, dari 7 responden atau 35\%. Sedangkan pada umur 41-50 tahun yang aktif 1 orang, yang kurang aktif 1 orang, lalu yang tidak aktif 2 orang, dari 4 responden atau 20\%. Sedangkan umur 51-60 tahun yang kurang aktif 3 orang, yang tidak aktif 2 orang, dari 5 responden atau $25 \%$. Sedangkan umur $>60$ tahun yang aktif 2 orang, yang tidak aktif 2 orang, dari 4 responden atau $20 \%$.

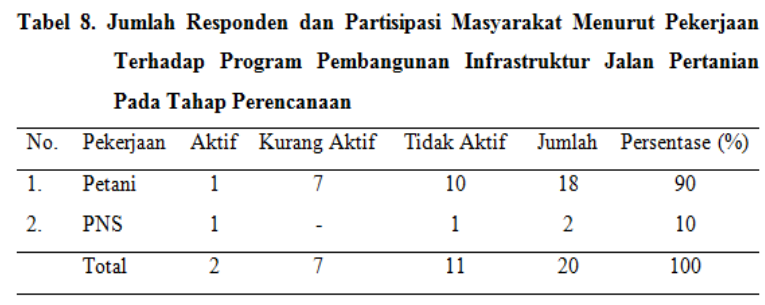

Tabel 8 dari hasil penelitian ini pekerjaan yang paling besar adalah petani yaitu ada 18 orang, lalu dimana ada 2 orang pekerjaannya sebagai PNS, dari tahap ini seluruh responden yang tidak aktif adalah 10 orang pada tahap perencanaan.

\begin{tabular}{|c|c|c|c|c|c|c|}
\hline \multicolumn{7}{|c|}{$\begin{array}{l}\text { Terhadap Program Pembangunan Ifrastruktur Jalan Pertanian Pada } \\
\text { Tahap Perencanaan }\end{array}$} \\
\hline No & Pendidikan & Aktif & Kurang Aktif & Tidak Aktif & Jumlah & Persentase (\%) \\
\hline 1. & SD & 2 & 3 & 2 & 7 & 35 \\
\hline 2. & SMP & - & 1 & 2 & 3 & 15 \\
\hline 3. & SMA & 2 & 3 & 3 & 7 & 35 \\
\hline 4. & PT & 1 & - & 1 & 2 & 10 \\
\hline & Total & 4 & 7 & 9 & 20 & 100 \\
\hline
\end{tabular}

Tabel 9 menujukkan bahwa tingkat pendidikan juga berpengaruh dalam tahap perencanaan yaitu tingkat SD yang aktif 2 orang yang kurang aktif 3 orang lalu yang tidak aktif 2 orang, dari 7 responden atau $35 \%$, dan tingkat SMP yang kurang aktif 1 orang lalu yang tidak aktif 2 orang dari 3 responden atau $15 \%$ dan tingkat SMA yang aktif 2 orang yang kurang aktif 3 orang lalu yang tidak aktif 3 orang dari 7 responden atau 35\% sedangkan tingkat PT yang aktif 1 orang yang tidak aktif 1 orang dari 2 responden atau $10 \%$. Responden tidak ikut berpartisipasi dengan alasan sibuk bekerja. 


\section{Tahap Pelaksanaan}

Pada Tahap pelaksanaan merupakan dimana kerja fisik dalam pembangunan infrastruktur jalan pertanian dilakukan dengan kerja fisik dalam suatu program tersebut, dimana membutuhkan kerja memlibatkan semua masyarakat untuk melakukan kegiatan dengan gotong royong bersama-sama, dalam pelaksanaan pembangunan infrastruktur jalan pertania, dengan partisipasi masyarakat diwujudkan dalam bentuk tenaga serta dengan peralatan dan sebagainya.

Tabel 10. Bentuk Partisipasi Dari Masyarakat dalam Tahap Pelaksanaan

\begin{tabular}{llcc}
\hline No & Bentuk Partisipasi & $\begin{array}{c}\text { Jumlah } \\
\text { (Responden) }\end{array}$ & $\begin{array}{c}\text { Persentase } \\
(\%)\end{array}$ \\
\hline 1. & Tenaga dan Barang & 3 & 15 \\
2. & Tenaga & 5 & 25 \\
3. & Tidak berpartisipasi & 12 & 60 \\
\hline & Total & 20 & 100 \\
\hline
\end{tabular}

Tabel 10 dari hasil penelitian ini masyarakat yang paling besar tidak berpartisipasi dalam pembangunan yaitu dimana 12 orang atau $60 \%$, dengan berbagai alasan maka tidak mengikuti dalam pelaksanaan, lalu yang ikuti berpartisipasi dalam bentuk tenaga yaitu ada 5 orang atau $25 \%$, sedangkan partisipasi dalam bentuk tenaga dan peralatan ada 3 orang atau $15 \%$, partisipasi masyarakat dalam tahap pelaksanaan dapat diukur dari wujud partisipasi masyarakat.

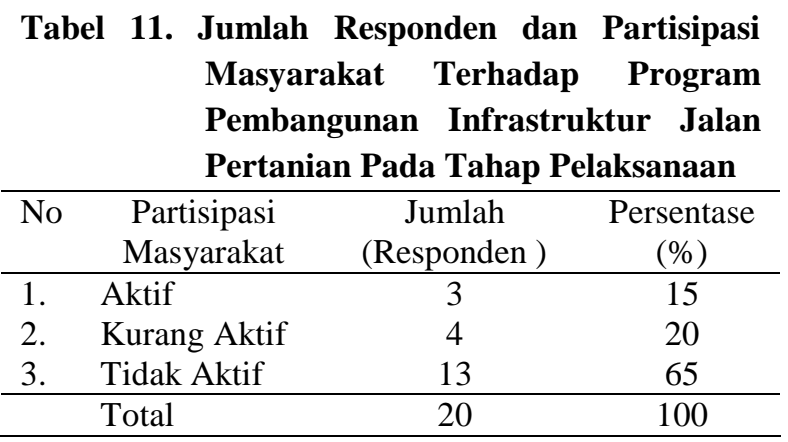

Tabel 11 dari hasil wawancara terlihat bahwa partisipasi masyarakat di Desa Kini, partisipasi yang terbesar adalah dalam pelaksanaan pembangunan infrastruktur jalan pertanian masyarakat yang aktif untuk berpartisipasi yaitu 13 orang atau $65 \%$, kemudian masyarakat yang kurang aktif yaitu 4 orang atau $20 \%$, lalu masyarakat yang aktif dalam pembangunan yaitu 3 orang atau $15 \%$.

Berdasarkan realisasi sumber pembiayaan dalam kegiatan ini adalah sebagai berikut: total biaya yang dikeluarkan pada PNPM-PPIP di Desa Kini adalah Rp.300.000,000 (tiga ratus juta), perincian dari Rp.300.000,000 juta ini Rp.100.000,000 dialokasikan untuk belanja barang-barang Rp.50.000.000 juta belanja barang-barang yaitu Sekop, Parang, Linggis, dan lain-lain, dan berupa bama yaitu Beras, minyak goring, garam, vitsin, gulah, kopi dan lain-lain, kalau Rp.50.000.000 juta pake pesawat kecil dua kali pelair antar alatalat/bama dan lain-lain, kalau Rp.200.000.000 juta merupakan partisipasi untuk masyarakat baik dari tenaga, maupun peralatan, bentuk partisipasi kepada semua masyarakat.

Tabel 12. Jumlah Responden Dalam Paritisipasi Masyarakat Menurut Umur
Pada Progam Pembangunan Infrastruktur Jalan Pertanian Pada
Tahap Pelaksanaan
\begin{tabular}{lcccccc}
\hline No & Umur & Aktif & Kurang Aktif & Tdak Aktif & Jumlah & Persentase (\%) \\
\hline 1. & $30-40$ & 1 & 2 & 4 & 7 & 35 \\
2. & $41-50$ & 1 & 2 & 2 & 5 & 25 \\
3. & $51-60$ & - & 1 & 2 & 3 & 15 \\
4. & $>60$ & 1 & 2 & 2 & 5 & 25 \\
\hline & Total & 3 & 7 & 10 & 20 & 100 \\
\hline
\end{tabular}

Tabel 12 menunjukkan bahwa responden yang aktif sebanyak 3 orang, lalu yang kurang aktif 7 orang yang tidak aktif 10 orang. Dimana ada umur 30-40 tahun yang aktif 1 orang, yang kurang aktif 2 orang, lalu yang tidak aktif 4 orang, tersebut tidak ambil bagian dalam tahap pelaksanaan. Sedangkan umur 41-50 tahun yang aktif 1 orang, yang kurang aktif 2 orang, lalu yang tidak aktif 2 orang. Sedangkan umur 51-60 tahun yang kurang aktif 1 orang, lalu yang tidak aktif 2 orang. Sedangkan umur $>60$ tahun yang aktif 1 orang, yang kurang aktif 2 orang, lalu yang tidak aktif 2 orang.

Tabel 13. Jumlah Responden Dalam Partisipasi Masyarakat Menurut Umur
dalam
$\begin{aligned} & \text { Pertanian Pada Tahap Pelaksanaan } \\
& \text { No }\end{aligned}$
\begin{tabular}{llcccccc}
\hline Pekerjaan & Aktif & Kurang Aktif & Tidak Aktif & Jumlah & Persentase (\%) \\
\hline 1. & Petani & 2 & 3 & 13 & 18 & 90 \\
2. & PNS & - & 1 & 1 & 2 & 10 \\
\hline & Total & 2 & 4 & 14 & 20 & 100 \\
\hline
\end{tabular}


Dari Tabel 13 menunjukkan bahwa dari 18 responden yang bekerja sebagai petani, yang aktif 2 orang, yang kurang aktif 4 orang, lalu 14 orang yang tidak mengambil bagian dalam pelaksanaan. Sedangkan PNS yang kurang aktif 1 orang lalu yang tidak aktif 1 orang, bekerja sebagai PNS.

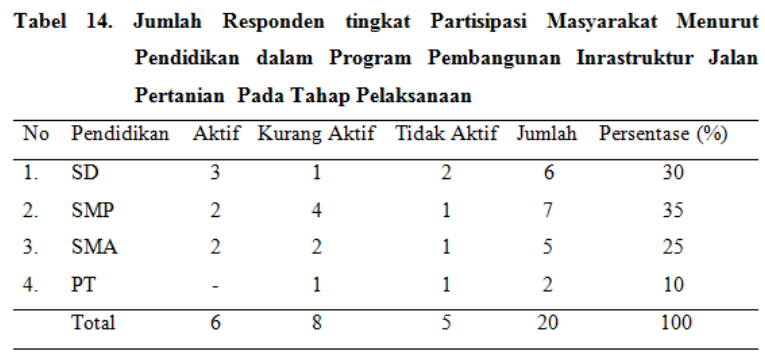

Tabel 14 melihat bahwa tingkat pendidikan SD yang aktif 3 reponden yang kurang aktif 1 responden, yang tidak aktif 2 responden, tingkat SMP yang aktif 2 responden, yang kurang aktif 4 responden, yang tidak aktif 1 responden, sedangkan tingkat SMA yang aktif 2 responden yang kurang aktif 2 responden, yang tidak aktif 1 responden, tingkat PNS yang kurang aktif 1 responden, yang tidak aktif 1 responden.

\section{Tahap Pemeliharaan}

Pada tahap pemeliharaan dimana masyarakat mengambil bagian untuk pembersihkan jalan sehingga jalan tersebut dengan terawat dan baik, semua itu dibutuhkan dalam partisipasi masyarakat diberikan dalam bentuk tenaga

Tabel 15. Bentuk Partisipasi Masyarakat Dalam Tahap Pemeliharaan

\begin{tabular}{llcc}
\hline No & Bentuk Partisipasi & $\begin{array}{c}\text { Jumlah } \\
\text { (Responden) }\end{array}$ & $\begin{array}{c}\text { Persentase } \\
(\%)\end{array}$ \\
\hline 1. & Tenaga dan Uang & - & - \\
2. & Tenaga & 20 & 100 \\
3. & Uang & - & - \\
4. & Tidak mengambil & - & - \\
& bagian & & 100 \\
\hline & Total & 20 & 100 \\
\hline
\end{tabular}

Dalam tahap pemeliharaan dengan bentuk partisipasi dimana ada 20 responden atau $100 \%$, dalam bentuk tenaga karena masyarakat hanya menyumbangkan tenaga dan peralatan untuk melakukan kerja bakti/pembersihan jalan tersebut.
Tabel 16. Jumlah Responden dan Partisipasi Masyarakat Terhadap Program Pembangunan Infrastruktur Jalan Pertanian Pada Pada Tahap Pemeliharaan

\begin{tabular}{llcc}
\hline No & $\begin{array}{c}\text { Partisipasi } \\
\text { Masyarakat }\end{array}$ & $\begin{array}{c}\text { Jumlah } \\
\text { (Responden) }\end{array}$ & $\begin{array}{c}\text { Persentase } \\
(\%)\end{array}$ \\
\hline 1. & Aktif & 14 & 70 \\
2. & Kurang Aktif & 4 & 20 \\
3. & Tidak Aktif & 2 & 10 \\
\hline & Total & 20 & 100 \\
\hline
\end{tabular}

Partisipasi masyarakat dalam tahap ini proses pemeliharaan dalam bentuk kerja bakti berjalan dengan baik, adapun masyarakat yang tidak mengambil bagian pada waktu kerja bakti mereka memberikan snack pagi yaitu makanan serta minuman sebagai pengganti.

Tabel 17. Jumlah Responden dan Partisipasi Masyarakat Menurut Umur
Terhadap Program Pembangunan Infrastruktur Jalan Pertanian
Pada Tahap Pemeliharaan
\begin{tabular}{lcccccc}
\hline No & Umur & Aktif & Kurang Aktif & Tidak Aktif & Jumlah & Persentase (\%) \\
\hline 1. & $30-40$ & 6 & 1 & 1 & 8 & 40 \\
2. & $41-50$ & 4 & - & 1 & 5 & 25 \\
3. & $50-60$ & 2 & 1 & 1 & 4 & 20 \\
4. & $>60$ & 2 & 1 & - & 3 & 15 \\
\hline & Total & 14 & 3 & 3 & 20 & 100 \\
\hline
\end{tabular}

Dari Tabel 17 ini dapat dilihat partisipasi masyarakat terhadap PPIP pada tahap pemeliharaan berdasarkan kategori umur. Responden berumur 30-40 tahun yaitu sebanyak 8 orang atau $40 \%$ dari 8 responden yang aktif 6 orang, yang kurang aktif 1 orang lalu yang tidak aktif 1 orang, sedangkan umur 41-50 tahun yaitu sebanyak 5 orang atau $25 \%$ yang aktif 4 orang, yang tidak aktif 1 orang sedangkan umur 50-60 tahun yaitu sebanyak 4 orang atau 20\% yang aktif 2 orang, yang kurang aktif 1 orang, lalu yang tidak aktif 1 orang, sedangkan umur $>60$ tahun yaitu sebanyak 3 orang atau 15\% yang aktif 2 orang, yang kurang aktif 1 orang.

Tabel 18. Jumlah Responden dan Partisipasi Masyarakat Menurut Pekerjaan Terhadap Program Pembangunan Infrastruktur Jalan Pertanian Pada Tahap Pemeliharaan

\begin{tabular}{llccccc}
\hline No & Pekerjaan & Aktif & Kurang Aktif & Tidak Aktif & Jumlah & Persentase (\%) \\
\hline 1. & Petani & 11 & 4 & 3 & 18 & 90 \\
2. & PNS & 1 & 1 & - & 2 & 10 \\
\hline & Total & 12 & 5 & 3 & 20 & 100 \\
\hline
\end{tabular}


Tabel 18 dari hasil penelitian ini menunjukkan bahwa petani yang aktif 11 orang, yang kurang aktif 4 orang, lalu yang tidak aktif 3 orang, dari 18 responden atau $90 \%$ sedangkan 2 responden bekerja sebagai PNS yang aktif 1 orang, yang kurang aktif 1 orang dari 2 responden atau $10 \%$.

Tabel 19. Jumlah Responden dan Partisipasi Masyarakat Menurut Pendidikan
Terhadap Program Pembangunan Infrasturktur Jalan
Pada Tahap Pemeliharaan
\begin{tabular}{llccccc} 
Nonian \\
\hline No & Pendidikan & Aktif & Kurang Aktif & Tidak Aktf & Jumlah & Persentase (\%) \\
\hline 1. & SD & 5 & 1 & 1 & 7 & 35 \\
2. & SMP & 3 & 1 & 2 & 6 & 30 \\
3. & SMA & 3 & 2 & - & 5 & 25 \\
4. & PT & 1 & - & 1 & 2 & 10 \\
\hline & Total & 12 & 4 & 4 & 20 & 100 \\
\hline
\end{tabular}

Tabel 19 melihat masing-masing tingkat pendidikan bahwa SD yang aktif 5 orang, yang kurang aktif 1 orang lalu yang tidak aktif 1 orang, dari 7 responden. Lalu tingkat SMP yang aktif 3 orang, yang kurang aktif 1 orang, yang tidak aktif 2 orang, dari 6 responden. Lalu tingkat SMA yang aktif 3 orang, yang kurang aktif 2 orang, dari 5 responden. Sedangkan tingkat PT yang aktif 1 orang, lalu yang tidak aktif 1 orang, dari 2 responden.

\section{Tingkat Partisipasi Masyarakat Terhadap Program Pembangunan Infrastruktur Perdesaan (PPIP)}

Tabel 20. Di kategorikan bahwa tingkat partisipasi masyarakat dari tahap perencanaan, tahap pelaksanaan, dan tahap pemeliharaan. Serta seluruh tingkat partisipasi dalam program pembangunan infrastruktur jalan pertanian di Desa Kini, di jelaskan bahwa bagaimana kategori tingkat partisipasi masyarakat.

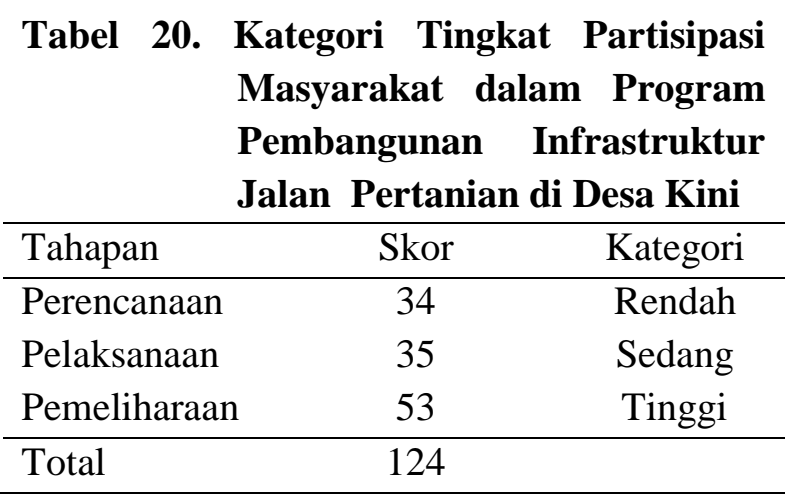

Dari hasil penelitian ini digunakan tiga kategori untuk mengukur tingkat partisipasi yaitu partisipasi rendah, sedang, dan tinggi. Pengukuran jumlah skor tinggi partisipasi dimana skor tinggi partisipasi masyarakat adalah 124 maka tingkat partisipasi masyarakat Desa Kini, berada di kategori tinggi dimana cara pengukuran tingkat partisipasi dilakukan penjumlah besarnya interval skor untuk menentukan kategori tingkat partisipasi masyarakat secarah menyeluruh didasarkan pada skor kategori tingkat partisipasi individu dikalikan dengan jumlah sampel, dibawa ini adalah penjelasan secara terperinci.

Terdapat 3 tahapan untuk melihat tingkat partisipasi individu masing-masing di berikan skor 1 sampai 3 . Sehingga minimum skor $(3 \times 1)$ adalah 3 , maksimum skor yang diperoleh $(3 \times 3)$ adalah 9, maka bilah jumlah sempel 20 dapat diketahui skor minimum untuk tingkat partisipasi masyarakat $(20 \times 3)$ adalah 60 dan skor maksimum (20x9) adalah 180 dengan diketahui skor minimum dan maksimum maka di ketahui juga jarak interval, yaitu (180-60) / 3 $=40$ maka tingkat partisipasi rendah berada pada 60 dan tinggi 180

Sedangkan mengukur tingkat partisipasi dalam setiap tahap yaitu tingkat partisipasi individu masing-masing dapat diberikan skor 1 sampai 3, dikarenakan hanya 1 tahapan yang dihitung maka minimum skor $(1 \mathrm{x} 1)$ adalah 1 dan maksimum skor (1x3) adalah 3, maka jumlah sampel 20, dapat diketahui skor minimum untuk tingkat partisipasi masyarakat (20x1) adalah 20 dan skor maksimum (20x3) adalah 60 , dengan diketahui skor minimum dan maksimum maka diketahui juga jarak interval yaitu (60-20) 13,3 maka tingkat partisipasi rendah berada pada 20 .

\section{KESIMPULAN DAN SARAN}

Kesimpulan
Partisipasi masyarakat dalam
bangunan infrastruktur jalan pertanian di
Kini, berada pada kategori yang sedang.
na dari ketiga tahapan pembangunan
kstruktur, tahap perencanaan dan tahap


masrayakat. Sedangkan tahap pemeliharaan merupakan tahapan yang paling banyak melibatkan partisipasi masyarakat, karena pada tahapan ini masyarakat telah merasakan hasil dari pembangunan infrastruktur akses jalan pertanian.

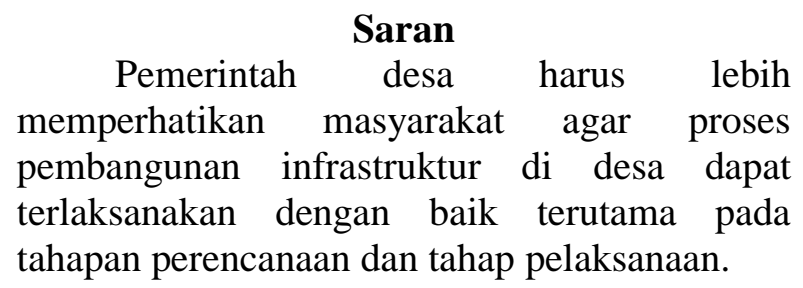

DAFTAR PUSTAKA

Adisasmita, Rahardjo. 2006. Pembangunan Pedesaan dan Perkotaan, Yogyakarta: Graha Ilmu.

PR INDONESIA. 2004. Undang-Undang Republik Indonesia Nomor 32 Tahun 2004 Tentang Pemerintahan Daerah. www.dpr.go.id. 